\title{
Review paper on Diagrid and Hexagrid structures
}

\author{
${ }^{1}$ Huzaifa Nakhwa, ${ }^{2}$ Prof. D. N. Kakade \\ ${ }^{1}$ PG Student, ${ }^{2}$ Professor, Civil Department, Civil Department, P.E.S College, Aurangabad, \\ Maharashtra, India.
}

\begin{abstract}
Out of the many feats of engineering in the twenty-first century the modern skyscraper is the most noticeable in the city architecture yet one of the least appreciated one. In the constantly evolving and expanding urban world the skyscrapers and the high rise in general helps to deal with many problems such as the accommodation of many different amenities in the same place and the optimum utilization of the precious resource in cities which is land. However, this engineering marvel comes with its own set of problems and challenges for the engineers with regards to its serviceability and safety criterion. As the height of the structure increases the lateral forces namely the earthquake and wind forces become more critical. To tackle these problems different structural systems are used such as Rigid frame, Shear wall, Outrigger structure, Tube system, Diagrid system, Pentagrid system and Hexagrid system. The two systems extensively researched and used now a days are Diagrid and Hexagrid systems.
\end{abstract}

Keywords - Diagrid, Hexagrid, utilization.

\section{INTRODUCTION}

Tall buildings are increasingly being constructed in big cities as they provide various remedies to the city's ever increasing land resource problems. Apart from providing serviceability and safety, engineers are exploring new ways to improve the buildings economy and usability. Tall buildings propose the most critical problems when it comes to resisting lateral loads. As the height of the building increases, wind and earthquake loads become more and more critical. To tackle these problems along with providing aesthetics, Diagrid, Hexagrid and other such systems are considered by designers. These systems consist of a mesh of support elements that are arranges in the form of triangles or hexagons or other types. This mesh surrounds the structure such that there is no need for the columns that are on the sides of the structure, moreover these systems provide good lateral support to the structure. There are many such types that can be used with different shapes and geometries and varying the angles and sizes of the systems lead to different properties. The type of system that is to be used generally depends upon the designer's choice but also on the requirement of the structure, the economy the site conditions and the zone in which the system is. Some of the work done on analysis of these systems is reviewed below.

Divya and Saraswathy[1] made a comparative study between Hexagrid diagrid and conventional system. The parameters for comparison were displacement, storey drift, shear force and modal time period. A 48 storied steel framed structure was selected for the study with different configurations. A total of 11 models were modelled using FEM based software ETABS. One conventional building model and five models for diagrid and five model for Hexagrid system were selected. The loading and other site conditions were taken from IS codes. The authors concluded that, with respect to the displacement on the top storey the conventional model had greater displacements as compared to Hexagrid and Diagrid models. The authors also commented that even as both Hexagrid and Diagrid models were very much effective in resisting shear forces and greatly reducing modal time period and drift of the structure, the Hexagrid is more economical than Diagrid system.

Varsani et al [2] compared between conventional structure and Diagrid structure in this study. The building configuration and model was kept nearly same for the study. Steel sections are used for the design as per IS codes and the loading and site conditions are also taken from IS codes. Story shear, drift, displacements and modal time period were selected as parameters for the comparison between the two models. The authors concluded that due to the diagonal columns the diagrid structure is very good in resisting lateral loads. The authors also observed that the displacement at the top story decreases as Diagrid structure is considered. Also there was increased internal space as commented by the authors.

Taranath et al [3] studied different variations of Pentagrid and Hexagrid systems. The authors used 40,50 and 60 storied frames for the study with variations such that the total number of frames accounted to 27. The different combinations of variations were tested like the combination of Hexagrid with flat slab and shear wall. The authors concluded that, Pentagrid systems are better than Diagrid systems in resisting lateral loads. Also as there is an 
increase in height the efficiency of Pentagrid system decreases and efficiency of Diagrid system increases.

Tripathi and Singla [4] investigated the differences between conventional and Diagrid system. The authors used 24, 36 and 48 storied RCC frame mathematical models for the study. A total of 15 models were considered for the study with variation of angle of diagrid. Beam and column sizes were also changed as per the storey requirement according to IS codes. The authors concluded that the diagrid angle between $65^{\circ}$ to $75^{\circ}$ were most promising with respect to lessening of time period, storey drift and storey shear. They also commented that as the time period is less mass of structure reduces and the stiffness is increased when the angle of diagrid is between the range of $65^{\circ}$ to $75^{\circ}$. Finally, the authors culminated that the results for Diagrid angle of $82.1^{\circ}$ was quite random and a proper conclusion for the same was not possible.

Pawar and Kakamare [5] used a 60 storey building with circular, rectangular and square plan configuration foe earthquake and wind analysis. FEM based software ETABS is used for mathematical modelling and analysis of the structure. Storey drift, base shear and storey displacement are considered for the analysis. The authors concluded that, the models considered were having displacements, shear forces and bending, moments within permissible limits according to IS codes. Circular and Square Diagrid systems had lower Storey Drift and Storey Displacements compared to Rectangular Diagrid system. Square Diagrid system had highest Base shear among the three systems. The authors commented that among the three systems square diagrid system performed the best.

Panchal and Patel [6] used a 72 meter 20 storied RCC frame to compare between conventional and Diagrid system. The building was designed for earthquake zone II and the site parameters are taken accordingly from IS codes. The beam and column sizes are same as far as interior of the structure is concerned but the outer columns are replaced by Diagrid system in model 2 for comparison. the size of the diagonal member was assumed to be $300 * 300$ at an angle of $78.2^{0}$ five different load combinations were taken and the parameters selected for comparison were story shear, drift, displacements and Quantity of material used for construction. The authors concluded that, the diagrid system was superior in all parameters mentioned above than conventional system along with being economical.

Manthan et al [7] compared conventional RCC framed structure to Diagrid system with emphasis on the material quantity that is needed for both the systems. The authors used seven buildings with $4,8,12,16,20,40$ and 28 number of storeys for diagrid system and conventional system. The mathematical models for the study were based on Indian standard codes. The authors concluded that the diagrid system provides high economy as regards to steel weight with added advantage of aesthetic appearance. The authors also commented that for one of the models weight of conventional frame building was double that of diagrid building.

Venkolath et al [8] analyzed a 24 storey RCC frame with circular plan to examine the most suitable diagrid angle in order to minimize the displacement and lateral drift of the structure. The authors used diagrid angles of $36.8^{\circ}, 56.3^{\circ}$, $66^{\circ}, 77.5^{\circ}$ and $83.6^{\circ}$. The authors compared the parameters such as lateral displacement, storey drift, and storey shear and time period. The authors concluded that diagrid angle in the range of $65^{\circ}$ to $75^{\circ}$ was best suited for diagrid system as it had the optimum stiffness. The storey shear, storey drift, modal time period were all superior than that of conventional building system.

Prasad et al [9] studied Hexagrid and Octagrid bracing systems for high rise buildings. The mathematical models of bracing systems of Octagrid and Hexagrid bracings are analyzed using ETABS software. The authors compared the top storey displacements, storey shears and the individual storey drifts between the two systems. The loadings on the structure along with the earthquake excitations and the Wind loads were taken from Indian standard codes. The authors concluded that Octagrid systems were marginally better at providing lateral resistance to wind and earthquake loads than Hexagrid systems. Also the material quantity used for Octagrid system was slightly less for Octagrid system thus making it slightly economical than Hexagrid system.

Saeed and Maryam [10] used 30 and 50 storey RCC framed structures with Tube, Diagrid Horizontal, Hexagrid and Combined Hexagrid system to study the effects of non linear static and dynamic earthquake excitations. The authors also performed Pushover analysis to investigate their performance in comparison to each other. The authors concluded that the Hexagrid systems both horizontal and combined outperformed the other two systems with respect to top story displacement. Also the Hexagrid systems showed superiority in resisting overall lateral displacement.

Lekshmi and Prasad [11] proposed a hybrid system consisting of Diagrid and tubular framed structure, the authors used three variations of percentages of tubular and diagrid. The combinations were $25 \%$ tubular and $75 \%$ diagrid, 50\% diagrid and 50\% tubular and lastly $25 \%$ diagrid and $75 \%$ tubular. All parameters were taken according to IS codes and the models were subjected to wind loads. Finite element based software ETABS was used for the mathematical modeling and analysis of the structures. The authors concluded that, the combination with $50 \%$ diagrid and $50 \%$ tubular structure was the best among the three combinations with regards to the storey displacement when subjected to wind loads. The authors also commented that the bracing system was very effective 
in resisting lateral loads and provided economy to the structure.

Jaswani and Dhyani [12] analyzed a 48 storey public building with Diagrid system. The authors used variation of diagrid angles and also varied the diagrid angles vertically. The authors attempted to find the best performing system when the structure is subjected to earthquake and wind loads. All building guideline data was taken from IS codes and the models were named alphabetically according to their variation of angles of the Diagrid. The authors concluded that, as far as wind loads were concerned it was recommended not to change the angle of the Diagrid and keep it uniform along the height of the structure. When earthquake excitations are considered the authors advised to use two angle variations in zone III but advised uniform angle for zone $\mathrm{V}$. lastly the authors commented that considering the overall structure uniform angle and 2-angle vertical variation namely $70^{\circ}$ and $76^{\circ}$ is recommended for Zone III and Zone V.

\section{CONCLUSION}

The comparison of lateral load resisting systems is done by the researchers in the above studies. Some researchers have compared the top storey displacement of conventional system with Diagrid system and found that diagrid system is superior in performance to Conventional system. Some researchers have compared the storey drift and storey shear of the diagrid, Hexagrid and conventional systems and found Hexagrid to be outperforming the other two systems. Hexagrid system was also found by some researchers to be more economical than other systems. Some authors also commented that these systems may it be Diagrid or Hexagrid resulted in more internal space as the obstructions from columns are minimized.

\section{REFERENCES}

[1] Divya M. S. and B. Saraswathy "Comparative Analysis of High Rise Steel Building with Hexagrid, Diagrid and Conventional Structural System" International Research Journal of Engineering and Technology, Volume 04, Issue: 04, Apr -2017, pp. 1902-1906

[2] Harish Varsani, Narendra Pokar and Dipesh Gandhi "Comparative Analysis of Diagrid Structural System and Conventional Structural System for High Rise Steel Building" International Journal of Advance Research in Engineering, Science \& Technology, Volume 02, Issue 01, January- 2015, pp. 1-5

[3] Taranath S. D., Mahantesh. N.B. and M. B. Patil "Comparative Study of Pentagrid and Hexagrid Structural System for Tall Building" Journal of Civil Engineering and Environmental, Volume 01, Issue 02; August, 2014 pp. 10-15

[4] Harshita Tripathi and Dr. Sarita Singla "Diagrid Structural System For R.C.Framed Multistoreyed
Buildings" International Journal of Scientific \& Engineering Research, Volume 07, Issue 06, June2016, pp. 356-362

[5] Shubhangi V. Pawar and M. S. Kakamare "Earthquake and Wind Analysis of Diagrid Structure" International Journal for Research in Applied Science \& Engineering Technology, Volume 05 Issue 07, July 2017, pp. 17291739

[6] Nishith B. Panchal and Vinubhai R. Patel, "Diagrid Structural System: Strategies to Reduce Lateral Forces on High-Rise Buildings" International Journal of Research in Engineering and Technology, Volume: 03 Issue: 04, Apr-2014, pp. 374-378

[7] Manthan I. Shah, Snehal V. Mevada and Vishal B. Patel "Comparative Study of Diagrid Structures with Conventional Frame Structures", int. Journal of engineering research and applications, Volume 06, Issue 05 May 2016, pp. 22-29

[8] Jayesh Venkolath, Rahul Krishnan K, “Optimal Diagrid Angle of High-Rise Buildings Subjected to Lateral Loads" International Research Journal of Engineering and Technology, Volume 03, Issue 09, September 2016, pp.841-846

[9] B K Raghu Prasad, Kavya A J and Amarnath K "Comparative Performance of Octagrid and Hexagrid Lateral Load Resisting Systems for Tall Building Structure" Int. Journal of Engineering Research and Applications, Volume 04, Issue 11, November 2014, pp.74-80

[10] Saeed Kia Darbandsari and Maryam Firoozi NezamAbadi "A Comparative Study on Seismic Performance of Hexagrid, Diagrid and Tubular Structural Systems" Journal of Structural Engineering and Geotechnics, Winter 2017, pp. 55 -65

[11]Lekshmi Mohan and C.K.Prasad Varma Thampan, "Numerical Modelling and Evaluation of Hybrid Diagrid Structures" International Journal of Research in Advent Technology Special Issue, June 2015, pp. 149-153

[12]Nilang R Jaswani and Prof. Dhruti J Dhyani "Parametric Study on Diagrid Structure System for High- Rise Building" International Journal of Advance Engineering and Research Development. Volume 02, Issue 05, May -2015, pp. 369-376. 